Journal of Patient-Centered

10-28-2019

\title{
Addressing Postpartum Smoking Relapse Among Low-Income Women: A Randomized Control Trial
}

Kristine Alaniz

Bruce Christiansen

Tingting Sullivan

Lisette Khalil

Michael C. Fiore

Follow this and additional works at: https://aah.org/jpcrr

Part of the Community Health Commons, Family Medicine Commons, Female Urogenital Diseases and Pregnancy Complications Commons, Maternal and Child Health Commons, Substance Abuse and Addiction Commons, and the Women's Health Commons

\section{Recommended Citation}

Alaniz K, Christiansen B, Sullivan T, Khalil L, Fiore MC. Addressing postpartum smoking relapse among low-income women: a randomized control trial. J Patient Cent Res Rev. 2019;6:233-42. doi: 10.17294/ 2330-0698.1702

Published quarterly by Midwest-based health system Advocate Aurora Health and indexed in PubMed Central, the Journal of Patient-Centered Research and Reviews (JPCRR) is an open access, peer-reviewed medical journal focused on disseminating scholarly works devoted to improving patient-centered care practices, health outcomes, and the patient experience. 


\title{
Addressing Postpartum Smoking Relapse Among Low-Income Women: A Randomized Control Trial
}

Kristine Alaniz, MPH, ${ }^{1}$ Bruce Christiansen, PhD, ${ }^{2}$ Tingting Sullivan, BS, ${ }^{1}$ Lisette Khalil, JD, MS, ${ }^{1}$ Michael C. Fiore, MD, MPH, MBA²

${ }^{1}$ Wisconsin Women's Health Foundation, Madison, WI; ${ }^{2}$ Center for Tobacco Research and Intervention, University of Wisconsin School of Medicine and Public Health, Madison, WI

\begin{abstract}
Purpose Smoking during pregnancy can have dire consequences for both the baby and mother. Low-income pregnant women smoke at particularly high rates. Among women who quit during pregnancy, postpartum relapse is high. This randomized control trial tested the effect of adding postpartum assistance to an existing smoking cessation program (First Breath) designed for low-income women.

Methods

Of 185 study participants, 94 women were randomly assigned to the standard First Breath program (control) and 91 to an enhanced program. First Breath consisted of evidence-based smoking cessation counseling provided at every prenatal visit. The enhanced program included all First Breath services plus 4 in-home counseling visits ( 3 postpartum), 3 postpartum counseling calls, support to others in the home, and incentives (gift cards) totaling $\$ 100$. The primary outcome was biochemically verified abstinence at 6 months postpartum.
\end{abstract}

Results Among the 98 women who completed the study, the abstinence rate among the intervention participants $(n=41)$ was significantly greater than among the control participants $(n=57)(36.6 \%$ vs $12.3 \%$, respectively; $\mathrm{P}<0.01$ ). Analyzed on an intent-to-treat basis, with those lost to follow-up assumed to be smoking, the abstinence rate among intervention subjects $(n=91)$ was $16.5 \%$ vs $7.4 \%$ among control participants ( $n=94) ; P=0.07$.

Conclusions Extending smoking cessation interventions into the postpartum period may help address postpartum relapse. (J Patient Cent Res Rev. 2019;6:233-242.)

Keywords randomized control trial; smoking cessation; nicotine dependence; socioeconomic status; pregnancy; postpartum; smoking relapse

$\mathrm{M}$ aternal smoking during pregnancy poses dire health consequences for both the baby and mother as well as significant financial costs. ${ }^{1-8}$ In 2016, $11.3 \%$ of pregnant women in Wisconsin reported smoking sometime during their pregnancy, ${ }^{9}$ higher than the national rate of $7.2 \%$. ${ }^{9}$ Smoking during pregnancy is more common among disadvantaged populations. ${ }^{10}$ Nationally, among Medicaid enrollees in 2014, 14.0\% smoked

Correspondence: Bruce Christiansen, PhD,

Center for Tobacco Research and Intervention, 1930 Monroe Street, Suite 200, Madison, WI 53711 (bc1@ctri.wisc.edu) vs $3.6 \%$ of those with private pay insurance. ${ }^{11}$ While smoking cessation programs for pregnant women are effective, ${ }^{12,13}$ postpartum relapse rates are high $(50 \%-$ $80 \%),{ }^{14-16}$ with low-income women and those with less education particularly likely to relapse. ${ }^{17,18}$

Likewise, while effective interventions that help pregnant women quit smoking are well documented, ${ }^{13}$ identifying interventions that prevent relapse postpartum has been more elusive. For example, $\mathrm{Su}$ and Buttenheim ${ }^{19}$ reviewed 32 studies of pharmacological, behavioral, and incentive-based interventions. While there was some evidence that such interventions decreased relapse early postpartum, the effects did not extend further into the postpartum period ( 9 to 12 
months). A recent Cochrane review and meta-analysis of relapse-prevention interventions in general found that interventions designed to prevent relapse in pregnant women who quit had no benefit at the end of pregnancy nor during the postpartum period. ${ }^{20} \mathrm{It}$ didn't matter if the relapse-prevention intervention occurred only in the prenatal, only in the postpartum, or across both periods.

Another Cochrane review ${ }^{13}$ found that counseling, incentives, and feedback, such as carbon monoxide (CO) tests, were effective. It also found that both counseling and incentives increase abstinence at 0 to 5 months postpartum compared to usual care but not when compared with less intense or alternative interventions. In addition, there was borderline evidence that counseling and strong evidence that incentives increased abstinence at 6 to 11 months compared to usual care. Finally, there was evidence that counseling increased smoking abstinence at 12 to 17 months postpartum.

In their review, Meernik and Goldstein ${ }^{21}$ reached a similar conclusion that combining behavioral strategies with incentives holds the most potential to reduce long-term postpartum relapse. ${ }^{21}$ Other research has suggested that incentives, typically money, gift cards, or vouchers that can be exchanged for items such as diapers, are effective in aiding smoking cessation, especially in low-income populations. ${ }^{22-29}$ Given the apparent intractable challenge of relapse after pregnancy, Likis et $\mathrm{al}^{22}$ recommended a multicomponent intervention and Chamberlain et $\mathrm{al}^{13}$ recommended local piloting of programs designed especially for socially disadvantaged populations. Additional candidates for a multicomponent intervention include home visits ${ }^{30}$ and addressing smoking by other household members. ${ }^{31-33}$

The potential of a multicomponent intervention was illustrated in a study by Gadomski et al. ${ }^{34}$ The intervention consisted of prenatal and postpartum counseling, regular $\mathrm{CO}$ monitoring postpartum, and incentives ( $\$ 20$ voucher towards the purchase of diapers every 3-4 weeks for up to 1 year, contingent on negative $\mathrm{CO}$ breath tests). Counseling was provided by certified cessation specialists, and participants saw the same cessation specialist whenever possible. Among women who completed the program, 77\% were abstinent at 3 months postpartum, $64 \%$ at 6 months, and $44 \%$ at 12 months.

The present study tests a multicomponent intervention, tailored to a population of low-income pregnant smokers, that combined elements identified as promising in the literature. The control group was an existing prenatal smoking intervention known to be effective, the First Breath program ${ }^{35}$ (described in Methods). The intervention group added elements to increase the intensity of the program: additional counseling delivered postpartum (both telephonically and during home visits), $\mathrm{CO}$ monitoring, incentives for accepting home visits and for abstinence, and education/support to other household members. The additional counseling in the intervention group was provided by tobacco treatment specialists, who remained the same for assigned women whenever possible. Primary outcome was biologically confirmed abstinence 6 months after delivery.

\section{METHODS}

The University of Wisconsin institutional review board approved this study. Participants were recruited from women enrolling in the First Breath (FB) program in 17 counties from 3 regions in eastern Wisconsin. FB, a program of the Wisconsin Women's Health Foundation (WWHF), has been in operation for 18 years. ${ }^{36}$ All pregnant women enrolling in FB in any of the target counties were eligible to participate. Women could join FB at any time during their pregnancy. Eligibility for FB and this study included pregnancy and currently smoking on a daily basis or having been daily smokers sometime in the past 6 months.

Eligible women were contacted via telephone and informed about the study. Those interested and providing verbal informed consent were randomly assigned to either the FB control group (essentially continuing in the program in which they were enrolled) or the enhanced intervention group (with additional services). Group assignment was random, blocking by region and race such that for each of the 3 geographic regions, 2 lists of random allocations (intervention vs control) were generated, 1 for white and 1 for nonwhite women. It was not possible to conceal group assignment from field staff, as data collection took 
place during the same calls (baseline) and home visits during which intervention elements were provided.

Study staff attempted to contact study participants 5 times via telephone, text, and letter before the participant was considered lost to follow-up.

\section{Control Group (First Breath Only)}

Women assigned to this group received the standard FB program - brief counseling (based on the 5 A's: Ask, Advise, Assess, Assist, and Arrange ${ }^{12}$ ) at 3 or more prenatal visits and 1 postpartum visit. This counseling was provided by existing staff (trained by WWHF staff) at FB sites, typically county public health departments or Women, Infants, and Children (WIC) clinics.

Staff at the FB sites were blinded to participants' study group assignments. Participants in this group also were provided a link to the Wisconsin Tobacco Quit Line (WTQL). At 6 months postpartum, WWHF research staff conducted a home visit to measure outcome. Participants received a \$20 gift card at enrollment in the FB program and a $\$ 20$ gift card for completing the 6-month home visit (Table 1).

\section{Enhanced Intervention Group (FB Plus Postpartum Services)}

Women assigned to this group received the same FB program delivered by staff in FB community sites. Additionally, they received 4 in-home counseling visits ( 1 prenatal and at 1, 3, and 6 months postpartum) and 3 postpartum counseling calls in months 2 , 4, and 5 (months where there were no home visits). Counseling and education were provided at every contact and included 20 discrete topics. Examples include: strategies to quit; benefits of quitting; triggers; cravings; withdrawal; slips and relapse; quit-smoking medicines; smoke-free home; social support; sudden infant death syndrome; stress; and mental health. $\mathrm{CO}$ testing was completed at every home visit. WWHF master-level research staff who were also trained tobacco treatment specialists delivered all counseling and education.

In addition to the $\$ 40$ in gift cards for the control group, intervention participants could earn an additional $\$ 100$ in gift cards ( $\$ 20$ each for the prenatal, 1-month, and 3-month postpartum home visit), and $\$ 20$ each for passing the $\mathrm{CO}$ test at the prenatal visit and the 6-month postpartum visit. The amount of the incentive $(\$ 20$ per event) was chosen to stay within the project's budget and be consistent with prior research using incentives with pregnant smokers trying to quit. For example, in a study of low-income Wisconsin pregnant women, Baker et $\mathrm{al}^{23}$ gave incentive amounts of $\$ 20-\$ 40$ per event. Another study provided vouchers worth $\$ 20$ that could be earned every 3-4 weeks for up to a year. ${ }^{34}$

Help also was provided to other household members and included education about supporting the cessation efforts of the mother, the need to reduce infant exposure

Table 1. Study Groups and Treatment Components

\begin{tabular}{l|l}
\hline Group & Components \\
\hline $\begin{array}{l}\text { Core First Breath } \\
\text { (prenatal only) }\end{array}$ & $\begin{array}{l}\text { - First Breath cessation counseling at all prenatal clinic visits delivered by First Breath site staff } \\
\text { - Link to Wisconsin Tobacco Quit Line } \\
\text { - One 6-month postpartum in-home abstinence evaluation visit (WWHF staff) } \\
-\$ 20 \text { gift card at enrollment and \$20 gift card for completing 6-month visit }\end{array}$ \\
$\begin{array}{l}\text { Expanded First Breath } \\
\text { (prenatal and postpartum } \\
\text { in-home visits) }\end{array}$ & $\begin{array}{l}\text { All Core First Breath components, plus: } \\
\text { 1 prenatal and 3 postpartum in-home counseling visits, including support to others in the home } \\
\text { - Additional \$100 in gift cards (\$20 each for the prenatal, 1-month postpartum, and 3-month } \\
\text { postpartum home visits, and \$20 each for passing the CO test at prenatal visit and 6-month } \\
\text { postpartum visit }\end{array}$ \\
\hline
\end{tabular}

CO, carbon monoxide; WWHF, Wisconsin Women's Health Foundation. 
to tobacco smoke, and how to establish a smoke-free home. Household members who smoked also were offered enrollment in a text-based smoking cessation program and/or a referral to the WTQL.

\section{Measurements}

Data were collected 4 times: via the phone at time of enrollment; and in-person during 3 home visits that took place prenatally, 1 month postpartum, and 6 months postpartum. These surveys were developed specifically for the FB program and for this research project, but included brief, validated scales (Online Appendices A and B).

Baseline Enrollment Survey: WWHF staff administered a telephone baseline survey at enrollment. The survey consisted of 31 questions: 9 demographic/ background questions; 5 stress/adjustment questions; and 17 tobacco-related questions.

Home Visit Surveys: These surveys included brief, established scales such as the Fagerstrom Test for Nicotine Dependence, ${ }^{37}$ the NIDA Quick Screen, ${ }^{38}$ the Patient Health Questionnaire (PHQ-9), ${ }^{39}$ and the Generalized Anxiety Disorder (GAD-7) scale. ${ }^{40}$ In addition, the 6-month postpartum survey included questions regarding abstinence, nonsmoking days, and daily number of cigarettes (11 items); cessation strategies (12 items); birth/baby outcomes (9 items); and historical pregnancy/child health events (9 items). In addition, $\mathrm{CO}$ was measured using piCO+ Smokerlyzer $^{\circledR}$ (coVita, Haddonfield, NJ). ${ }^{41}$

SPSS Statistics for Windows, Version 22.0 (IBM, Armonk, NY) was used to test for group differences. Nominal items were analyzed using chi-squared test (Fisher's exact test when cell size was less than 5), while interval items and Likert rating scales were analyzed using t-tests.

\section{RESULTS}

Of the 372 women enrolled in FB and referred to this study, $248(66.7 \%)$ were successfully contacted. Of these, $185(74.6 \%)$ were eligible and agreed to participate, with 94 women randomly assigned to the control group (FB) and 91 to the intervention group (FB plus postpartum services). A total of 98 women (53.0\%) completed the 6-month postpartum visit (Figure 1).

\section{Baseline Survey}

Average age of the 185 study participants was 28.5 years, the average gestational age at enrollment was 27 weeks, and $54 \%$ of participants were black/ African American (Table 2). The overall sample was disadvantaged: $54.2 \%$ reported less than $\$ 10,000$ in annual family income; $32.8 \%$ had a high school diploma or GED and $27.9 \%$ less than a high school education; $59.0 \%$ were unemployed; and $58.2 \%$ were single. Of 185 participants, $34.8 \%$ reported a mental illness, and $20.8 \%$ reported a substance use disorder. Most $(82.9 \%)$ reported that their goal was to quit smoking permanently.

The average age that study participants reported starting smoking regularly was 16.5 years; $65.0 \%$ smoked the week prior to enrollment, and $89.9 \%$ of these smoked 10 cigarettes or fewer per day. For those not smoking at the time of enrollment, $45.3 \%$ had not smoked for between 1 and 3 months. Of those smoking at enrollment, $23.0 \%$ smoked within 5 minutes of waking whereas $44.3 \%$ waited an hour or more before their first cigarette. In addition to smoking cigarettes, $14.8 \%$ used e-cigarettes and $9.8 \%$ smoked cigars/cigarillos.

The average household size was 4.4 people, with 2.5 of these being children. For $57.9 \%$ of the women, they were the only smoker in the home; $39.3 \%$ lived with 1 or 2 other smokers, and $2.7 \%$ had 3 or more other smokers. Smoking was not allowed in the home for $51.7 \%$ of study participants; $36.1 \%$ permitted smoking only in designated rooms within the house; and $1.2 \%$ permitted smoking anywhere in the home.

There were no statistically significant differences between control and intervention participants on any of the 31 baseline questions, with one exception. More women in the intervention group reported that they had made a quit attempt in the past year compared to women in the control group $(83.5 \% \mathrm{vs}$ $71.7 \%$, respectively; $\mathrm{P}=0.04$ ).

\section{Drop Out Analysis}

More intervention participants were lost to follow-up than control participants ( $54.9 \%$ vs $39.4 \%$, respectively; $\mathrm{P}=0.04)$. Those lost to follow-up differed from those not lost on 5 of the 31 baseline measures, including 


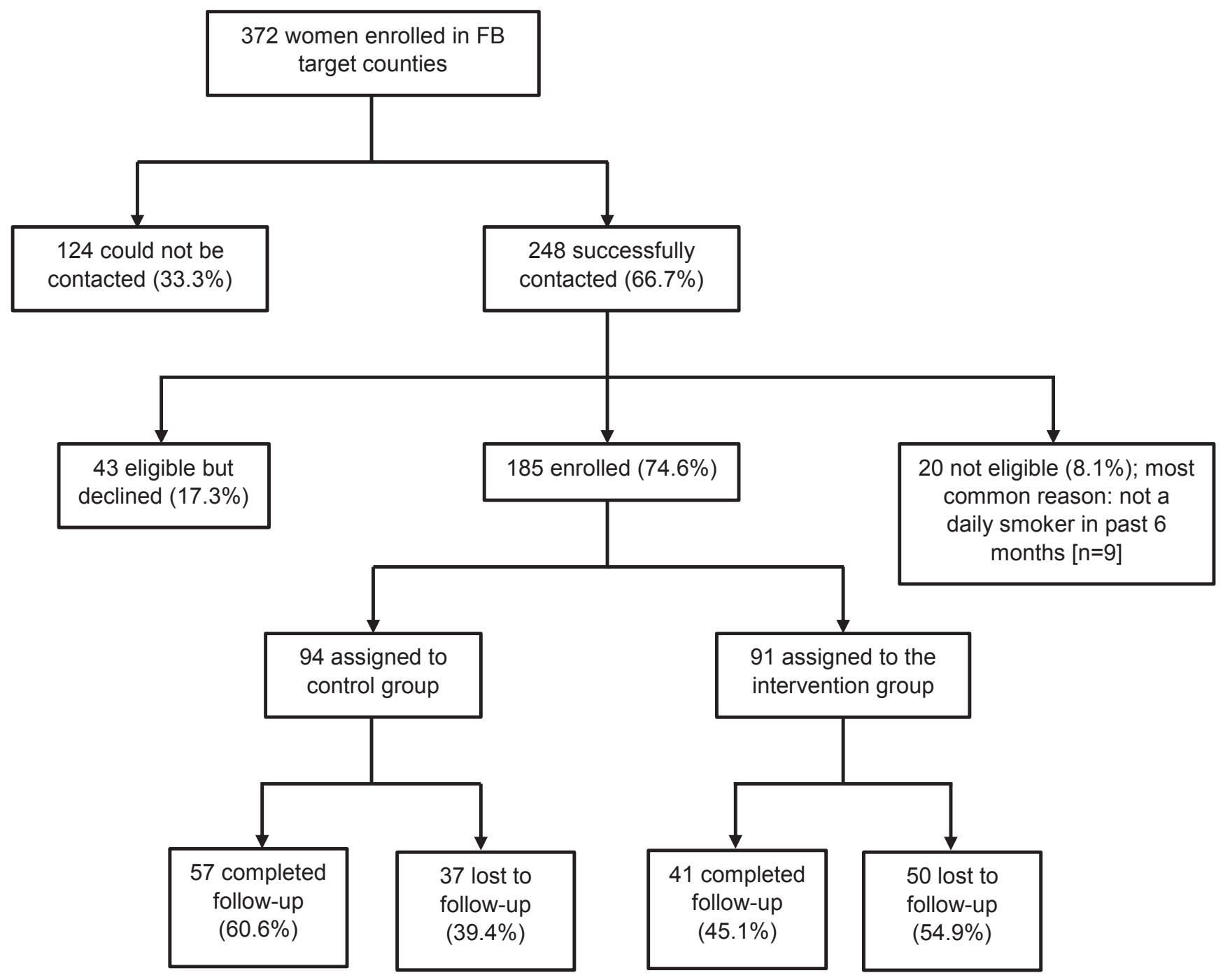

Figure 1. Study enrollment.

that they were younger (27.1 vs 29.9 , respectively; $\mathrm{P}<0.001)$ and less likely to be single $(49.4 \%$ vs $66.3 \%$, respectively; $\mathrm{P}=0.048$ ).

\section{Delivery of Postpartum Services}

Intervention participants received, on average, 214 more minutes of counseling than control participants (standard deviation: 93.9; minimum: 10; maximum: 435). Of the 20 counseling topics, more than $90 \%$ of the women discussed an action plan (95.7\%), smoking history (93.5\%), cravings (93.5\%), and the benefits of quitting (93.5\%). Least frequently addressed topics were how to adjust to postpartum life (17.4\%), sudden infant death syndrome (15.2\%), and weight management (6.5\%).
Within the intervention group, $46.7 \%$ of the women consented to be referred to the WTQL. Support/ education also was available for other household members, who could receive referral to a stop-smoking text program and/or the WTQL if they smoked. Support was given to 34 adults across 21 women and 1 child of a participant. For study participants, $8.7 \%$ had at least one household person referred to both a cessation text program and the WTQL, $8.7 \%$ had at least one household person referred to only the text program, and $4.3 \%$ had at least one household member referred to only the WTQL. The counselors rated the level of engagement as low for $23.9 \%$ of these women, medium for $30.4 \%$, and high for $45.7 \%$. Counselors 
Table 2. Baseline Comparisons - Treatment Versus Control

\begin{tabular}{|c|c|c|c|c|}
\hline Variable & $\begin{array}{l}\text { Total Sample } \\
\quad(\mathrm{N}=185)\end{array}$ & $\begin{array}{l}\text { Treatment } \\
\qquad(n=91)\end{array}$ & $\begin{array}{c}\text { Control } \\
(n=94)\end{array}$ & $P$ \\
\hline \multicolumn{5}{|l|}{ Demographic } \\
\hline Mean age, years & 28.5 & 28.3 & 28.8 & 0.46 \\
\hline Mean gestational age, weeks & 27.1 & 27.4 & 26.9 & 0.70 \\
\hline Race & & & & 0.64 \\
\hline Black/African American & $54.4 \%$ & $54.4 \%$ & $54.3 \%$ & \\
\hline White & $31.3 \%$ & $31.1 \%$ & $31.5 \%$ & \\
\hline Bi- or multi- & $8.8 \%$ & $8.9 \%$ & $8.7 \%$ & \\
\hline Other & $5.5 \%$ & $5.5 \%$ & $5.4 \%$ & \\
\hline Ethnicity, Hispanic/Latino & $10.4 \%$ & $11.0 \%$ & $9.8 \%$ & 0.81 \\
\hline Current household income (5 categories), $<\$ 10,000$ & $54.2 \%$ & $59.1 \%$ & $49.5 \%$ & 0.53 \\
\hline Education (5 categories), high school/GED & $32.8 \%$ & $31.9 \%$ & $33.7 \%$ & 0.27 \\
\hline Employment (3 categories), not employed & $59.0 \%$ & $54.9 \%$ & $63.0 \%$ & 0.42 \\
\hline Relationship status (4 categories), single & $58.2 \%$ & $56.0 \%$ & $60.4 \%$ & 0.67 \\
\hline Mean number of people in household & 4.4 & 4.37 & 4.42 & 0.85 \\
\hline \multicolumn{5}{|l|}{ Stress/Adjustment } \\
\hline Diagnosed with mental illness, yes & $34.8 \%$ & $32.2 \%$ & $37.4 \%$ & 0.68 \\
\hline Substance use disorder, yes & $20.8 \%$ & $17.0 \%$ & $24.4 \%$ & 0.30 \\
\hline Mean stress (1=extremely low, $5=$ extremely high) & 3.25 & 3.20 & 3.29 & 0.62 \\
\hline Mean number of specific stresses during pregnancy $(0-14)$ & 1.69 & 1.59 & 1.79 & 0.55 \\
\hline Mean daily support from others ( $1=$ extremely low, $5=$ extremely high) & 3.52 & 3.46 & 3.57 & 0.60 \\
\hline \multicolumn{5}{|l|}{ Tobacco-Related } \\
\hline Tobacco goal & & & & 0.68 \\
\hline Reduce while pregnant & $4.4 \%$ & $4.4 \%$ & $4.4 \%$ & \\
\hline Reduce permanently & $5.0 \%$ & $3.3 \%$ & $6.7 \%$ & \\
\hline Quit while pregnant & $7.7 \%$ & $6.6 \%$ & $8.9 \%$ & \\
\hline Quit permanently & $82.9 \%$ & $85.7 \%$ & $80.0 \%$ & \\
\hline Mean age of regular use & 16.5 & 16.7 & 16.2 & 0.40 \\
\hline First a.m. cigarette & & & & 0.15 \\
\hline Within 5 minutes & $23.0 \%$ & $24.2 \%$ & $21.7 \%$ & \\
\hline $6-30$ minutes & $17.5 \%$ & $11.0 \%$ & $23.9 \%$ & \\
\hline $31-60$ minutes & $15.3 \%$ & $16.5 \%$ & $14.1 \%$ & \\
\hline$>60$ minutes & $44.3 \%$ & $48.4 \%$ & $40.2 \%$ & \\
\hline Smoke in past week, yes & $65.0 \%$ & $63.7 \%$ & $66.3 \%$ & 0.42 \\
\hline For smokers: cigarettes/day (5 categories), $1-5$ & $57.1 \%$ & $58.6 \%$ & $55.7 \%$ & 0.21 \\
\hline For non-smokers: duration of non-smoking & & & & 0.86 \\
\hline$<2$ weeks & $4.7 \%$ & $6.1 \%$ & $3.2 \%$ & \\
\hline 2-4 weeks & $14.1 \%$ & $12.1 \%$ & $16.1 \%$ & \\
\hline $1-3$ months & $45.3 \%$ & $48.5 \%$ & $41.9 \%$ & \\
\hline $3-6$ months & $35.9 \%$ & $33.3 \%$ & $38.7 \%$ & \\
\hline Mean confidence in being smoke free in a year ( $1=$ not at all, $5=$ very) & 3.78 & 3.80 & 3.76 & 0.79 \\
\hline Mean motivation to quit/remain quit ( $1=$ not at all, $5=$ greatly $)$ & 4.50 & 4.42 & 4.57 & 0.19 \\
\hline Heaviest daily smoking & & & & 0.90 \\
\hline $1-5$ & $18.6 \%$ & $18.7 \%$ & $18.5 \%$ & \\
\hline $6-10$ & $26.8 \%$ & $26.4 \%$ & $27.2 \%$ & \\
\hline $11-15$ & $9.3 \%$ & $11.0 \%$ & $7.6 \%$ & \\
\hline $16-20$ & $32.8 \%$ & $33.0 \%$ & $32.6 \%$ & \\
\hline $21-30$ & $9.8 \%$ & $7.7 \%$ & $12.0 \%$ & \\
\hline $31-40$ & $2.7 \%$ & $3.3 \%$ & $2.2 \%$ & \\
\hline Smoked during previous pregnancy (if applicable), yes & $69.5 \%$ & $70.1 \%$ & $68.9 \%$ & 0.51 \\
\hline Number of others in household who smoke ( 3 categories), none & $57.9 \%$ & $59.3 \%$ & $56.5 \%$ & 0.87 \\
\hline Quit attempt in past year, yes & $77.6 \%$ & $83.5 \%$ & $71.7 \%$ & 0.04 \\
\hline
\end{tabular}

GED, General Educational Development. 
rated the difficulty to reach and complete appointments as easy for $43.5 \%$ of these participants, medium for $26.1 \%$, and high for $26.1 \%$.

\section{Primary Outcome}

Abstinence was defined as self-reporting no smoking and achieving a breath sample of $<6 \mathrm{ppm} \mathrm{CO} .^{42}$ (Six women self-reported that they smoked at least one cigarette in the past week who, nonetheless, achieved a CO measurement of less than $6 \mathrm{ppm}$. Conservatively, these were categorized as smokers.) The abstinence rate among the intervention participants who completed the study $(n=41)$ was significantly greater than the abstinence rate among the control participants who completed the study ( $\mathrm{n}=57)(36.6 \%$ vs $12.3 \%$, respectively; $\mathrm{P}<0.01)$. Analyzed on an intent-totreat basis, with those lost to follow-up assumed to be smoking, the abstinence rate among intervention subjects $(n=91)$ was $16.5 \%$ while the abstinence rate among control participants $(\mathrm{n}=94)$ was $7.4 \%$, a difference that was not statistically significant $(\mathrm{P}=0.07)$.

Two types of women were enrolled in the project: those who were smoking at the time of enrollment and wanted help to quit (65\% of enrollees) and those who had recently quit and wanted help remaining abstinent (35\% of enrollees). For the former, the primary outcome (CO-confirmed abstained) represented successfully quitting. For the latter, it represented continued abstinence. Abstinence rates did not differ significantly based on smoking status at the time of enrollment.

\section{Additional Findings}

There were no differences between the groups on additional variables when a Bonferroni correction was applied for multiple comparisons. For example, there were no differences in mean days of nonsmoking, motivation to quit/remain quit, number of cigarettes smoked daily (among those still smoking), mean birth weight, and mean weeks of gestation.

Those who quit also were compared with those who did not, regardless of group assignment. Women who quit reported greater mean birth weight than those who did not quit (3130 grams vs 2858 grams, respectively; $\mathrm{P}=0.04$.). Not surprisingly, those who quit reported greater confidence about being smoke free in a year than nonquitters (mean of 4.5 vs mean of 3.5 [on a $1-5$ scale], respectively; $\mathrm{P}<0.01$ ) and greater motivation to quit/remain quit versus nonquitters (mean of 4.9 vs mean of 3.8 [on a $1-5$ scale], respectively; $\mathrm{P}<0.01$ ).

From a list of 14 stressors, those who quit endorsed fewer stressors than those who did not quit (1.3 vs 2.6, respectively; $\mathrm{P}=0.01$ ). Those who quit were not less likely to have other adults in the home who smoked. However, those who quit reported higher day-to-day emotional support $(\mathrm{P}=0.02) ; 50 \%$ of those who quit reported extremely high emotional support vs $28.8 \%$ of those who did not quit, $35.0 \%$ vs $15.1 \%$ reported fairly high emotional support, respectively, $10.0 \%$ vs $21.9 \%$ reported medium emotional support, respectively, $3.0 \%$ vs $11.0 \%$ reported fairly low emotional support, respectively, and $5.0 \%$ vs $15.1 \%$ reported extremely low emotional support, respectively.

Those who quit were more likely to be breastfeeding at the time of follow-up than nonquitters $(15.0 \%$ vs $1.4 \%$, respectively; $\mathrm{P}=0.01$ ). Quitters were more likely to report having tried to quit cold turkey than nonquitters ( $85.7 \%$ vs $60.8 \%$, respectively; $\mathrm{P}=0.04$ ), while those who quit were less likely to report cutting down/reducing than nonquitters $(33.3 \%$ vs $63.5 \%$, respectively; $\mathrm{P}=0.02$ ).

\section{DISCUSSION}

This study suggests that the enhanced FB program was potentially more effective in promoting abstinence than the existing FB program, although further enrollments should be assessed. This enhanced program differed from FB in multiple ways. It extended counseling into the high-relapse-risk postpartum period (thereby providing more counseling), included in-home visits, provided education and support to others in the home, provided incentives, and was delivered by tobacco treatment specialists dedicated to smoking cessation rather than staff at FB sites who were responsible for all prenatal care. Within the literature on smoking cessation during pregnancy, a consensus is emerging that extending care postpartum and using incentives improves outcome. ${ }^{13,21-29,34}$ There is also support for treatments to be provided by cessation specialists. ${ }^{34}$

The control group used in our study, ie, those enrolled in the original First Breath program, is characterized 
as a "less intense" control group rather than a "usual care" control group. The literature has found significant intervention effects for interventions when compared to usual care but not when compared to a less intense intervention. For example, Chamberlain et al conducted meta-analyses of 102 trials enrolling more than over 28,000 women. ${ }^{13}$ Across 3 postpartum time periods ( 0 to 5 months, 6 to 11 months, and 12 to 17 months) there was evidence for an effect of counseling and incentives when compared to usual care. However, when the intervention was compared to a less intense intervention, the evidence for interventions consisting of counseling, incentives, and/or social support was described as "uncertain" for each of the postpartum time periods. The results of our study, which used a less intense intervention as the control group, are consistent with this literature and suggest the need for continued research.

The intervention tested by Gadomski et al, which included counseling, incentives, and feedback, ${ }^{34}$ was most similar to the intervention tested in our study. Their study compared the intervention when delivered by dedicated cessation counselors who worked with the same women over time with the same intervention delivered by providers in community settings such as WIC clinics who had other responsibilities. There was more counseling provided when it was done by the dedicated staff. Thus, like in our study, the comparison group (though not randomly assigned as was our control group) was a less intense intervention. Gadomski and colleagues reported higher abstinence at 6 months postpartum (64\%) than our study, although they did not calculate abstinence on an intent-to-treat basis.

About $47 \%$ of those enrolled did not complete the 6-month follow-up visit, reflecting the difficulties of reaching and treating this population. It is also imperative to understand the reasons for the significant attrition rate in our study so that steps can be taken to increase treatment retention.

\section{Limitations}

The study's greatest limitation is small sample size, resulting in reduced statistical power. Consequently, a more than doubling of abstinence ( $7.4 \%$ vs $16.4 \%$, intent-to-treat analysis) failed to demonstrate a statistically significant difference $(\mathrm{P}=0.07)$. More than doubling of abstinence rates among intervention participants suggests a clinically meaningful difference that must be confirmed in a study with greater power. For example, a sample size of 240 (vs 185 in the current study) would have provided enough statistical power to detect a $7.4 \%$ vs $16.4 \%$ difference. Another limitation was self-reported outcomes apart from smoking abstinence. For example, birth weights were not confirmed with birth records.

Finally, as a multicomponent intervention, it is not possible to attribute any particular treatment effect to any particular intervention element. Assuming that a larger study with a bigger sample and greater statistical power confirms the effect noted here, then future research could assess the relative contributions of the various treatment elements. These limitations notwithstanding, this study adds to the emerging literature emphasizing that extending support into the postpartum period enhances success among pregnant women who smoke.

\section{CONCLUSIONS}

Women who quit smoking during pregnancy, even those who receive evidence-based cessation treatment, tend to relapse postpartum. Our results suggest a benefit to low-income pregnant women who smoke from an enhanced intervention that includes 1) extending cessation interventions postpartum in addition to counseling and education, 2) support and help to others in the home, 3) CO test feedback, and 4) incentives for both accepting services and for biochemically confirmed abstinence.

\section{Patient-Friendly Recap}

-While efforts to help women quit smoking while they are pregnant can prevent serious health consequences for both baby and mother, many women start smoking again soon after the baby is born.

- Providing additional help after the baby is born, both over the telephone and at home visits, can help new moms avoid relapse.

- This help includes additional counseling and support, help to others in the family, and gift cards for remaining smoke free. 


\section{Acknowledgments}

The authors would like to acknowledge Wendy Theobald, PhD, of the University of Wisconsin-Madison for her assistance in preparing this manuscript.

\section{Author Contributions}

Study design: Christiansen, Khalil, Fiore. Data acquisition or analysis: all authors. Manuscript drafting: Christiansen. Critical revision: Alaniz, Christiansen, Khalil, Fiore.

\section{Conflicts of Interest}

None.

\section{Funding Sources}

This work was supported by the University of Wisconsin-Madison Clinical and Translational Science Award program, through a National Institutes of Health's National Center for Advancing Translational Sciences grant (UL1TR000427).

\section{References}

1. Scherman A, Tolosa JE, McEvoy C. Smoking cessation in pregnancy: a continuing challenge in the United States. Ther Adv Drug Saf. 2018;9:457-74. CrossRef

2. Centers for Disease Control and Prevention (US); National Center for Chronic Disease Prevention and Health Promotion (US); Office on Smoking and Health (US). How Tobacco Smoke Causes Disease: The Biology and Behavioral Basis for Smoking-Attributable Disease: A Report of the Surgeon General. Atlanta, GA: Centers for Disease Control and Prevention (US), 2010.

3. Shah NR, Bracken MB. A systematic review and meta-analysis of prospective studies on the association between maternal cigarette smoking and preterm delivery. Am J Obstet Gynecol. 2000;182:465-72. CrossRef

4. Adams EK, Miller VP, Ernst C, Nishimura BK, Melvin C, Merritt R. Neonatal health care costs related to smoking during pregnancy. Health Econ. 2002;11:193-206.

5. Pineles BL, Park E, Samet JM. Systematic review and metaanalysis of miscarriage and maternal exposure to tobacco smoke during pregnancy. Am J Epidemiol. 2014;179:807-23. CrossRef

6. Dietz PM, England LJ, Shapiro-Mendoza CK, Tong VT, Farr SL, Callaghan WM. Infant morbidity and mortality attributable to prenatal smoking in the U.S. Am J Prev Med. 2010;39:45-52. CrossRef

7. Zhang K, Wang X. Maternal smoking and increased risk of sudden infant death syndrome: a meta-analysis. Leg Med (Tokyo). 2013;15:115-21. CrossRef

8. Adams EK, Melvin CL, Raskind-Hood C, Joski PJ, Galactionova E. Infant delivery costs related to maternal smoking: an update. Nicotine Tob Res. 2011;13:627-37. CrossRef

9. Centers for Disease Control and Prevention. Table 1 from "Cigarette smoking during pregnancy: United States, 2016." NCHS data brief 305 (2018). Available at: https://www.cdc. gov/nchs/data/databriefs/db305 table.pdf.

10. Drake P, Driscoll AK, Matthews TJ. Cigarette smoking during pregnancy: United States, 2016. NCHS Data Brief. 2018;(305):1-8. Available at: https://www.cdc.gov/nchs/data/ databriefs/db305.pdf.
11. Curtin SC, Matthew TJ. Smoking prevalence and cessation before and during pregnancy: data from the birth certificate, 2014. Natl Vital Stat Rep. 2016;65(1):1-14. Available at: https://www.cdc.gov/nchs/data/nvsr/nvsr65/nvsr65_01.pdf.

12. Tobacco Use and Dependence Guideline Panel. Treating Tobacco Use and Dependence: 2008 Update. Rockville, MD: US Department of Health and Human Services, 2008.

13. Chamberlain C, O’Mara-Eves A, Porter J, et al. Psychosocial interventions for supporting women to stop smoking in pregnancy. Cochrane Database Syst Rev. 2017;2:CD001055. CrossRef

14. Jones M, Lewis S, Parrott S, Wormall S, Coleman T. Restarting smoking in the postpartum period after receiving a smoking cessation intervention: a systematic review. Addiction. 2016;111:981-90. CrossRef

15. Prady SL, Kiernan K, Bloor K, Pickett KE. Do risk factors for post-partum smoking relapse vary according to marital status? Matern Child Health J. 2012;16:1364-73. CrossRef

16. Rockhill KM, Tong VT, Farr SL, Robbins CL, D’Angelo DV, England LJ. Postpartum smoking relapse after quitting during pregnancy: pregnancy risk assessment monitoring system, 2000-2011. J Womens Health (Larchmt). 2016;25:480-8. CrossRef

17. Letourneau AR, Sonja B, Mazure CM, O’Malley SS, James D, Colson ER. Timing and predictors of postpartum return to smoking in a group of inner-city women: an exploratory pilot study. Birth. 2007;34:245-52. CrossRef

18. Harmer C, Memon A. Factors associated with smoking relapse in the postpartum period: an analysis of the child health surveillance system data in Southeast England. Nicotine Tob Res. 2013;15:904-9. CrossRef

19. Su A, Buttenheim AM. Maintenance of smoking cessation in the postpartum period: Which interventions work best in the long-term? Matern Child Health J. 2014;18:714-28. CrossRef

20. Livingstone-Banks J, Norris E, Hartmann-Boyce J, West R, Jarvis M, Hajek P. Relapse prevention interventions for smoking cessation. Cochrane Database Syst Rev. 2019;2:CD003999. CrossRef

21. Meernik C, Goldstein AO. A critical review of smoking, cessation, relapse and emerging research in pregnancy and post-partum. Br Med Bull. 2015;114:135-46. CrossRef

22. Likis FE, Andrews JC, Fonnesbeck CJ, et al. Smoking Cessation Interventions in Pregnancy and Postpartum Care. AHRQ Publication No. 14-E001-EF. Rockville, MD: Agency for Healthcare Research and Quality (US), 2014.

23. Baker TB, Fraser DL, Kobinsky K, et al. A randomized controlled trial of financial incentives to low income pregnant women to engage in smoking cessation treatment: effects on post-birth abstinence. J Consult Clin Psychol. 2018;86:464-73. CrossRef

24. Zhang X, Devasia R, Czarnecki G, Frechette J, Russell S, Behringer B. Effects of incentive-based smoking cessation program for pregnant women on birth outcomes. Matern Child Health J. 2017;21:745-51. CrossRef

25. Higgins ST, Washio Y, Heil SH, et al. Financial incentives for smoking cessation among pregnant and newly postpartum women. Prev Med. 2012;55 Suppl:S33-40. CrossRef

26. Lumley J, Chamberlain C, Dowswell T, Oliver S, Oakley L, Watson L. Interventions for promoting smoking cessation during pregnancy. Cochrane Database Syst Rev. 2009(3):CD001055. CrossRef 
27. Boyd KA, Briggs AH, Bauld L, Sinclair L, Tappin D. Are financial incentives cost-effective to support smoking cessation during pregnancy? Addiction. 2016;111:360-70. CrossRef

28. Ierfino D, Mantzari E, Hirst J, Jones T, Aveyard P, Marteau TM. Financial incentives for smoking cessation in pregnancy: a single-arm intervention study assessing cessation and gaming. Addiction. 2015;110:680-8. CrossRef

29. Tappin D, Bauld L, Purves D, et al. Financial incentives for smoking cessation in pregnancy: randomised controlled trial. BMJ. 2015;350:h134. CrossRef

30. Chalmers K, Gupton A, Katz A, et al. The description and evaluation of a longitudinal pilot study of a smoking relapse/ reduction intervention for perinatal women. $J$ Adv Nurs. 2004;45:162-71. CrossRef

31. Simmons VN, Sutton SK, Quinn GP, Meade CD, Brandon TH. Prepartum and postpartum predictors of smoking. Nicotine Tob Res. 2014;16:461-8. $\underline{\text { CrossRef }}$

32. Lemola S, Grob A. Smoking cessation during pregnancy and relapse after childbirth: the impact of the grandmother's smoking status. Matern Child Health J. 2008;12:525-33. CrossRef

33. Donatelle RJ, Prows SL, Champeau D, Hudson D. Randomised controlled trial using social support and financial incentives for high risk pregnant smokers: Significant Other Supporter (SOS) program. Tob Control. 2000;9 Suppl 3:III67-69. CrossRef

34. Gadomski A, Adams L, Tallman N, Krupa N, Jenkins P. Effectiveness of a combined prenatal and postpartum smoking cessation program. Matern Child Health J. 2011;15:188-97. CrossRef
35. Jehn L, Lokker N, Matitz D, Christiansen B. First Breath prenatal smoking cessation pilot study: preliminary findings. WMJ. 2003;102(3):29-34.

36. Alaniz K, Christiansen B, Sullivan TT, Khalil L, Fiore MC. Helping low income women quit smoking: improving the First Breath program. WMJ. (in press).

37. Heatherton TF, Kozlowski LT, Frecker RC, Fagerström KO. The Fagerström Test for Nicotine Dependence: a revision of the Fagerström Tolerance Questionnaire. $\mathrm{Br} J$ Addict. 1991;86:1119-27. CrossRef

38. National Institute on Drug Abuse. The NIDA Quick Screen. Last updated 2012 Mar. https://www.drugabuse.gov/ publications/resource-guide-screening-drug-use-in-generalmedical-settings/nida-quick-screen. Accessed May 15, 2019.

39. Kroenke K, Spitzer RL, Williams JB. The PHQ-9: validity of a brief depression severity measure. J Gen Intern Med. 2001;16:606-13. CrossRef

40. Spitzer RL, Kroenke K, Williams JB, Löwe B. A brief measure for assessing generalized anxiety disorder: the GAD-7. Arch Intern Med. 2006;166:1092-7. CrossRef

41. coVita. piCO+ Smokerlyzer ${ }^{\circledR}$. https://www.covita.net/wpcontent/uploads/2019/09/pico-manual.pdf. Accessed February 4, 2019.

42. Deveci SE, Deveci F, Açik Y, Ozan AT. The measurement of exhaled carbon monoxide in healthy smokers and nonsmokers. Respir Med. 2004;98:551-6. CrossRef

(C) 2019 Aurora Health Care, Inc. 